\title{
Introduction: Social Epistemology Meets the Philosophy of the Humanities
}

\author{
Anton Froeyman • Laszlo Kosolosky • \\ Jeroen Van Bouwel
}

Published online: 9 September 2014

C) Springer Science+Business Media Dordrecht 2014

From time to time, when I explain to a new acquaintance that I'm a philosopher of science, my interlocutor will nod agreeably and remark that that surely means I'm interested in the ethical status of various kinds of scientific research, the impact that science has had on our values, or the role that the sciences play in contemporary democracies. Although this common response hardly corresponds to what professional philosophers of science have done for the past decades, or even centuries, it is perfectly comprehensible. For there are large questions of the kinds just indicated, questions that deserve to be posed and answered, and an intelligent person might well think that philosophers of science are the people who do the posing and the answering (Kitcher in Science, truth and democracy. Oxford University Press, Oxford, p. xi, 2001).

This programmatic passage from the very first page of Philip Kitcher's Science, Truth and Democracy is probably one of the most concise and accurate descriptions of the aims and motivations that underlie much of the recently developed (sub)discipline of social epistemology. However, although we whole-heartedly agree with the spirit of this quote, there is one point where we believe Kitcher got it wrong. By saying that the common conception of philosophy of science does not correspond to what philosophers of science have been doing for the past decades or centuries, Kitcher expresses the widespread idea that it is somewhat natural for philosophers of science to occupy themselves with topics such as causation, evidence, realism or laws, and only to a lesser extent with ethics, politics, policy, management or economy.

There are, however, good reasons to believe that this widespread idea is a misconception. In How the Cold War Transformed Philosophy of Science, Reisch (2005) makes it admirably clear that the ideal of a 'pure' philosophy of science, untouched by the profane interests of society outside academia, is a mere historical contingency. It is not a mindset that comes

The authors are listed alphabetically, and would like to stress the equality of their contribution to this introduction and volume.

A. Froeyman $(\bowtie) \cdot$ L. Kosolosky $\cdot$ J. Van Bouwel

Ghent University, Ghent, Belgium

e-mail: Anton.Froeyman@ugent.be 
natural to philosophers, not even to philosophers of science. Rather, it is a historically contingent way of thinking, prompted by specific political and social circumstances. Reisch argues that, contrary to what is often thought, the Vienna Circle originally never intended to purify philosophy of science from all things ethical, political or ideological. On the contrary, the original project of logical empiricism, embodied especially in the work of Otto Neurath, started off with an explicitly leftist political agenda. Ironically, it was only through the pressure of politicians and groups outside the university (Joseph McCarthy and J. Edgar Hoover's FBI) that logical empiricism, and with it philosophy of science as a whole, started to cultivate the idea that it should keep clear of the world outside science.

Logical empiricism, however, was not the only pre-World War II tradition in which the social aspects of science were investigated. In his very last book, Edmund Husserl, the founding father of phenomenology, gave an account of the development of science, pointing to the human 'life-world' as the forgotten foundation of science. According to Husserl (1970), science was losing its ability to give meaning to human life and civilization. Hence, It was philosophy's task then to restore the lost connection between science and the life-world. Husserl's intentions were shared by another important phenomenologist and neo-Kantian: Ernst Cassirer. Cassirer (1977) started his career as a historian of philosophy and as what we would now call a traditional philosopher of science: someone who analyzes scientific theories on internal consistency and empirical adequacy. (See Cassirer 2003) In the course of his work, however, he realized that his account was incomplete, and he went on to explore the foundations of science in language, myth, religion and art.

In short, before the Second World War, in the heydays of logical empiricism and phenomenology and at the birth of existentialism, the idea that philosophy of science should limit itself to the study of the internal structure of scientific theories was all but non-existent. And even when it did became a more or less general ideal (during the 50's and 60's), it did not last long. Philosophers of science have realized that science does not take place in a vacuum.

As a response to the vacuum conjectures, studying the intriguing relation between science and society became one of the focal points in building a new discipline called social epistemology. Social epistemological research arose as an epistemological reaction against the division between philosophy of science, as it was practiced in the years after WW II, and, sociology of science, which developed as a subdiscipline of sociology in the early 1970's. The difference between these two disciplines can be seen as a difference between a mainly normative and a mainly empirical discipline. Whereas traditional philosophers of science (and epistemologists) focused more on grasping the right methodological rules that a single, rational scientist should pursue, sociologists of science (and researchers within science studies in general) describe and explain the social history of science.

As said, social epistemologists aspire to transcend this division. Historically speaking, the first time 'social epistemology' was used as a term was (probably) in the writings of library scientist, Jesse Shera, who in turn credited his associate Margaret Egan. "[S]ocial epistemology," Shera says, "is the study of knowledge in society.... The focus of this discipline should be upon the production, flow, integration, and consumption of all forms of communicated thought throughout the entire social fabric." (Shera 1970, p. 86, Goldman 2014) Shera's agenda, however, was very different from that of current-day social epistemology, which only began to emerge in the late 1980s. The first special issue on social epistemology appeared in October 1987 in the philosophical journal Synthese (guest edited by Frederick F. Schmitt). Among the contributors were Stewart Cohen, Hilary Kornblith, Frederick F. Schmitt, Keith Lehrer, Margaret Gilbert, Alvin Goldman and Steve Fuller. All of them, and many more in their footsteps, have since then put the discipline on the map. Especially Goldman and Fuller made considerable contributions to the field: Fuller founded the journal Social Epistemology 
and published a book with the same title in 1988. Goldman, on the other hand, published his Knowledge in a Social world in 1999, and is currently Senior Advisory Editor of the journal Episteme, which was founded in 2004.

Although the discipline itself has moved in many directions and knows many faces, we can define two central characteristics: First, social epistemologists emphasize the social or collective aspect of science and knowledge in general, as opposed to an individualistic approach in the traditional philosophy of science and epistemology; scientists accept claims as a result of interaction with, and mutual dependence of, others (and society in general). Methodological rules are always to comprise rules on how the social interaction between scientists should look like and how institutions should be shaped accordingly. Second, social epistemologists do not conclude that the social character of knowledge gaining is necessarily a source of bias or irrationality that would undermine or negatively influence the acceptance of true (or truth conforming) statements. This in contrast to much of sociology of science. Trying to find out the characteristics of these irrational interactions (cascades, pluralistic ignorance, group thinking, et cetera) such that they could ideally be identified and addressed, is often the aim. Social epistemologists regard the social dimension as constitutive for good knowledge and see it as their duty to sort out how the quest for knowledge should be organized-including its social (and institutional) dimensions. Social epistemologists do normative research, without hereby losing grip on the social dimension of knowledge.

Up until now, we have argued that the ideal of philosophy of science as it being about an ideal, isolated rational scientist is a historical contingency, and that the arrival of social epistemology is actually not a real innovation, but rather a recovery of themes that were generally seen as essential to philosophy of science. One could think that, through the development of social epistemology, philosophy of science has returned to its proper place, and again treats the whole spectrum of science as a philosophically relevant topic. However, we believe that this is not quite the case. It is true that social epistemology addressed some of the blind spots of post-WWII philosophy of science. But it did not address all of them. We are talking in particular about how the term 'science' is understood. In the English-speaking world, the term 'science' usually refers to the natural sciences and the life sciences, sometimes including (or excluding) the social sciences. Hence, 'philosophy of science' was and still is mainly about the natural sciences, to a somewhat lesser extent about the life sciences, to an even slighter extent about the social sciences, and not at all about the humanities. In continental Europe however, the very same term ('science' in French, 'Wissenschaft' in German) has always been used to denote any kind of systematic way of knowledge-gathering, including the social sciences, the humanities and often even philosophy itself. Hence, there are good reasons to at least consider broadening the scope of philosophy of science to include these disciplines. This is especially promising with respect to social epistemology. Parallel to mainstream analytical philosophy of science, there have been major discussions about science, values and society within the theory and methodology of the social sciences and the humanities.

The discussion started at the end of the nineteenth century with the so-called Baden-school of Neo-Kantianism, which was in opposition with the Marburg-school of Neo-Kantianism that eventually lead to Logical Empiricism. Philosophers of the Baden-school such as Rickert and Dilthey tried to account for the growing success of the humanities in the nineteenth century by providing it with a special status as a 'value-laden' form of science. (Dilthey 2002; Rickert 1986) Their statements lead to a large-scale discussion on the role of values, objectivity and partisanship in the humanities. The loci classici for the opposing camp, the one that argued for a value-neutral conception of science, were two essays by the sociologist Max Weber: The Meaning of "Ethical Neutrality" in Sociology and Economics and "Objectivity" in Social Science and Social Policy. (Weber 2011a,b) Weber wrote these as a response to an 
older generation of explicitly political scholars, the so-called Kathedersozialisten ('Armchair Socialists'), and advocated a strict separation between fact and value.

However, the history of the humanities in the twentieth century proved Weber wrong. Many of the most important discussions and developments in the humanities and the social sciences revolved around the relation between scholarly disciplines and society. Historians for example have always been conscious of the use and abuse of history, most explicitly as a way of legitimizing nationalism or imperialism (Anderson 1991; Berger and Lorenz 2008; Iggers 1983; Ehrecht 1979), and many of the most important historiographical discussions, such as the Historikerstreit in Germany and the History Wars in Australia, the United States and Japan or the discussion about world history versus Western Civilization (see Peter Stearns' article in this volume) have revolved around questions of nationalism and collective guilt. (See Knowlton and Cates 1993; Macintyre and Clark 2003; Linenthal and Engelhardt 1996) Furthermore, in the course of the twentieth century, several new disciplines arose within the humanities that are explicitly and uncompromisingly political. Think of gender studies, postcolonial studies and subaltern history. Practitioners of these disciplines openly use 'scientific' (in the continental sense) study in order to achieve a political and ethical goal: to expose oppression of minorities and 'others', and to provide developing nations with a more positive identity.

What is striking is that these discussions in the humanities and the social sciences have gone practically unnoticed by mainstream analytical philosophers of science. The theoretical basis of these discussions was mostly if not exclusively provided by practitioners of the disciplines themselves: by anthropologists, historians, postcolonial scholars..., or by theorists who specialized in the theory of the humanities. This is particularly regrettable in the light of the development (or should we say resurrection?) of social epistemology, because the discussions and development of the humanities and social sciences might be a veritable treasure chest of case studies for social epistemologists. Theorists from the humanities and social sciences, on the other, could learn valuable new frameworks and methods from mainstream philosophy of science. Hence, the aim of this volume is to bring these fields together, by collecting a number of essays from both disciplines.

In the next subsections we will draw on some thematic overlaps of the papers present in this special issue, both to give the reader a first impression of what they will argue for in their full paper, as well as to signal points of interaction, dispute and suggestions for future research.

\section{Consensus and Dissent}

Boaz Miller warns us for the idea that we should resort to consensus to decide legal and policy-related issues. As an example he draws on the U.S. Federal Courts' decision to favor the scientific consensus that the drug Bendectin could not cause birth defects in human babies, under the assumption that only a scientific consensus amounts to knowledge. Miller argues that this was a mistake: we can only defer to a consensus when that consensus is knowledge-based, or grounded in knowledge shared by its members, as opposed to mere agreement (which is not necessarily of epistemic value). Regarding the simple fact of a scientific consensus over a certain view as a sufficient reason to believe that this view is correct, ignoring the more specific argumentation of the different parties taking part in the consensus, is mistaken.

This idea of a knowledge-based consensus is defined by three conditions that must jointly be met: social calibration (i.e. genuine agreement must be present), apparent consilience of evidence (i.e. epistemic robustness must be ensured), and social diversity. 
Stegenga, as he mentions in his paper, agrees that consilience is important, though he does not explicitly demand it as a desideratum for consensus conferences. Its importance can be understood in relation to the three desiderata he devised for these conferences: inclusivity (all available evidence should be included), constraint (intersubjective assessments of the hypothesis of interest should be constrained) and evidential complexity (evidence should be assessed on the multiple relevant evidential criteria). His argument goes as follows:

[Inclusivity] is a necessary condition for a thoroughgoing consilience (since an easy but unsatisfying way of achieving consilience would be to only include evidence which is concordant and exclude all evidence which is discordant); to the extent that consilience is a truly compelling epistemic desideratum, it can be construed as a sufficient condition for achieving [constraint] (since if all available evidence confirms one hypothesis over its rivals, we would demand of a consensus conference that its conclusions be constrained to support this hypothesis over its rivals). Consilience, however, is not a necessary condition for achieving [constraint], because even if different modes of evidence support different hypotheses, the consensus conference could have techniques (analytic or otherwise) for achieving [constraint] despite the discordant evidence. (Stegenga)

As can be taken from the quote above, Miller and Stegenga basically agree about the relation between consensus and knowledge. Both are convinced the two should not be conflated. Stegenga, in this vein, puts forth constraint, inclusivity and evidential complexity as three desiderata that consensus conferences should meet. Although these desiderata may not be exhaustive-Stegenga himself shows the importance of social inclusivity-they do incorporate the important epistemic aspects of the desiderata of Miller's knowledge-based consensus. Stegenga argues, by referring to two case studies, that consensus conferences are good at satisfying inclusivity and evidential complexity, but considerably worse at constraint.

However, when we read King, Morgan-Olsen and Wong's claims on the dual impact of dissent on deliberation, we can question constraint as a desideratum for consensus conferences. If constraint were met, then insights of dissenting opinions and evidence could be lost. Solomon (2006) and Mill (1859/1991) are only two of the advocates of this concern. Stegenga, who is well aware of this objection, comments that loss of dissent is indeed a concern, but only if constraint is achieved cheaply, by ignoring the complexity and diversity of evidence (that is, by ignoring inclusivity and evidential complexity). If both are satisfied, then, whether or not constraint is met, by stipulation the diversity and complexity of evidence is not ignored. Regardless, according to Stegenga, the satisfaction of constraint need not involve the silencing of dissent. (Stegenga).

Despite their firm claims on the connection between knowledge and consensus, there are subtle yet striking nuances in the way both authors coin their phrases. When it comes to consensus that is not knowledge-based, Miller says:

It is important to stress that the fact that a consensus is not knowledge based does not necessarily mean that the consensual view is false or unwarranted. Rather, it means that the fact that an agreement exists does not carry additional credence for the view that is being agreed upon. It does not give us a reason to infer that it is true from the mere fact that a consensus exists over it. (Miller)

In other words, Miller states that the mere fact that an agreement exists in an epistemic community does not carry epistemic weight. It does not give us any reason to believe that $\mathrm{p}$ over and above the reasons the members of the community have to believe that $\mathrm{p}$. It may still be the case that these reasons alone are compelling and sufficient for justifiably believing 
that p, or it may not (Miller). However, when it comes to the value of consensus itself, Miller is rather convinced that once a consensus does not classify as a knowledge-based consensus, courts and policy makers cannot use consensus as an epistemic resource in itself (by deferring to it) as frequently as they do.

When it comes to defining his three desiderata, Stegenga both stresses that this list is not exhaustive and argues for a loose understanding of the terms. In the case of constraint, for example, he says the following:

Constraint should be construed loosely-intersubjective assessments of competing hypotheses, say, or estimations of the magnitude of a parameter, should be constrained to at least some (unspecified) degree by an amalgamation method. (Stegenga)

However, when Stegenga discusses the examples, in order to show the absence of constraint in both instances, the weaker wording is easily lost.

Apart from the apparent difference in rigidity of their claims, both authors seem eager to safeguard the value of consensus and consensus conferences and hence formulate their views rather extremely: a consensus or consensus conference is either epistemically valuable (when it is knowledge-based and we can defer to it), or it has no epistemic value at all. There seems little room for a grey zone.

In recent work (Kosolosky and Van Bouwel 2014), two authors of this article argue that consensus conferences do have added epistemic value, ${ }^{1}$ in the sense that they can contribute to both epistemic adequacy and contestability. We distinguish between academic consensus and interface consensus and show how the difficulties of achieving consensus understood as a unanimous outcome - a seldom-attained ideal stipulated by a range of criteria - should encourage us to shift to a procedural approach in which the emphasis is not so much on establishing a consensus, but on dealing with plurality in a consensual way, i.e. framed within a meta-consensus by which we agree on how to disagree. Briefly put, our view entails a consensus on the procedure of how to achieve consensus, hence a meta-consensus. Since a group can do everything in its power to reach a consensus by going through the proper procedure, they are not forced to let a position stand as the group's afterwards (see Beatty and Moore 2010), nor are they forced to mask or construct a false consensus (with or without misidentified dissent). ${ }^{2}$ After having gone through the procedure, the group is rather given the opportunity to communicate their state of agreement in the sense they deem fit considering the demands of the situation at hand. They can, for example, suspend their judgment until further evidence is available, only endorse a view when there is unanimous agreement, portray the agreement as is in terms of how many people agree and how many disagree, agree by means of taking a majority vote, or what have you. This social procedural approach tries to surpass the extreme view of all or nothing, and rather tries to show the value consensus-making can have while properly accounting for valuable dissent.

Our own paper does not settle the argument of which way is the best, but rather puts forth different ways of thinking about consensus making, each having their own particular values at certain occasions. We interpret Stegenga's and Miller's papers from a similar point of

1 And correspondingly undermine Solomon's claim that "Consensus conferences seem to miss the intended window of epistemic opportunity: they typically take place after the experts reach consensus." (Solomon 2007, p. 170), a claim Stegenga refers to in order to illustrate that Solomon also suggests that consensus conferences fail to achieve constraint.

2 Views like Tucker (Tucker 2003, pp. 509-510), that state that agreement amounts to consensus only when it is complete and there is no dissent whatsoever, could in practice result in consensus being ill-constructed by improperly spelling out dissent, just for the sake of being able to appeal to consensus in arguing for or against a certain position. 
view: not as a competition about who is right and who is wrong, but as valuable contributions that show that different ways of creating consensus can have different implications for both policy and the advancement of knowledge. This is equally the case for its mirror image, dissent: as King, Morgan-Olsen and Wong show, there are varieties of disagreement that can motivate varieties of dissent. King et al. offer a taxonomy that establishes a more finegrained conceptualization of forms of dissent, aimed at the level of policies and proposals. By doing this, they are offering us a potential tool for minimizing miscategorization and maximizing effective uptake, distinguishing full assent, attenuated assent, full dissent and attenuated dissent (King, Morgan-Olsen \& Wong). So, there are different kinds of dissent and consensus, some valuable, some misidentified and some even detrimental, and sorting out these differences is both a difficult and time-consuming undertaking. If done correctly, it will certainly improve our understanding of this intricate relation between heterodoxy and orthodoxy, or pluralism and consensus.

\section{Social-Epistemic Dynamics, Democracy and Commercialization}

In his contribution, Hugh Lacey pays attention to the role science can play in strengthening democratic values and practices. This presupposes the inclusion of a broad range of value outlooks that are actually held in a democratic society. According to Lacey, current science is mainly serving one particular value outlook. It is characterized by commercialization and uses a narrow scientific methodology driven by decontextualizing research strategies (DS), as opposed to contextualizing research strategies (CS). Lacey advocates methodological pluralism, i.e., employing both DS and CS, in order to develop possible alternatives to the dominant DS scientific research. Alternatives that might, for instance, be of greater value for the underprivileged or marginalized in society, or for those motivated by sustainability and social justice rather than techno-scientific efficiency and economic gain. Developing these alternatives also provides us with the opportunity to identify and compare the potential risks of the various approaches. Science characterized by such a methodological pluralism would ensure that a broader range of value outlooks could be addressed. This would then strengthen democracy-Lacey refers, inter alia, to respect for human rights and the capacity of citizens to assume active, responsible and participatory roles in shaping the practices that address their basic necessities.

Then, how to challenge "the hegemony of private interest science" that Lacey sketches? How to assure the neutrality, impartiality and autonomy of science? Lacey envisions a mix of strategies that would be worked out in a democratic dialogue involving both scientists and representatives of all the value outlooks that are viable in contemporary societies. He sees a responsibility for scientists to act according to the ideals of neutrality, impartiality and autonomy. This responsibility cannot be exercised by scientists unless appropriate social conditions and institutions of science, are available. According to Lacey, this is currently not the case. He presents several points of entry to rehabilitate the ideals of science (e.g., the use of the Precautionary Principle, the participation of citizens, reflection on democratic values, appropriate forms of scientific education, ...).

While Lacey studies the impact of science on democracy, its values and practices, Loren King, Brandon Morgan-Olsen and James Wong discuss how to import democracy (and democratic theory) into science and the challenges the democratization of science faces. Democratizing science is often understood as aiming for a greater deliberative inclusion within science, including all relevant perspectives in the community of researchers. King et al. temper the expectations about greater deliberative inclusion by pointing at the growing body of 
empirical work identifying opportunities, but also systematic barriers to effective inclusive deliberation in both scientific and political settings. Think, for instance, of the work in social psychology that finds that groups are easily polarized by deliberation (Sunstein 2007) and that there is a clear tradeoff between participation and deliberation in the face of disagreement (Mutz 2006). Or think of the work of Jackman and Paul (2006) that suggests that everyday political argument and deliberation do not seem to have much effect on subsequent beliefs.

King, Morgan-Olsen and Wong focus on cases where deliberations can be framed in such a way that dissent is systematically misidentified, classifying unsettled dissent too easily as irresolvable worldview agonism. They analyze several examples of miscategorization in public political discourse and, by doing so, they hope to inform the advocates of the democratization of scientific knowledge. The ultimate goal is to design safeguards against these destructive tendencies so that their analysis of misidentified dissent - properly distinguishing the kinds of difference and disagreement motivating dissent — can be of use for the practical implementation of more democratic ways of doing science. Furthermore, the empirical findings about deliberative democracy can also help us to substantiate our philosophical account of the conditions, the mediating structures, under which effective deliberation proceeds.

Indeed, central to the effectiveness of an inclusive deliberative process - and the democratization of science-is to have social-epistemic processes among the plurality of approaches that are productive and maximize uptake, i.e., not merely tolerating dissenting views, but taking seriously and reacting to each other's position. Reflecting on the social-epistemic processes and the mediating structures (formal institutions, cognitive heuristics and biases, cultural norms, etc.) that are working between pre-deliberative inputs and post-deliberative judgments, studying democratic theory turns out to be very fruitful (also see Van Bouwel 2009). It helps us to evaluate the processes and mediating structures already in place as well as analyze the viability of changing or replacing these structures.

Attention to the social dynamics and the institutional conditions highlights the social nature of human justificatory practices; these deliberations are not just taking place in an abstract space of propositional content, as King, Morgan-Olsen and Wong rightly emphasize. The social nature of justificatory practices is also the focus of Saana Jukola's paper on objectivity. She challenges traditional views of objectivity associated with the behavior of individual scientists and advocates a social view that considers suitable conditions for critical socialepistemic interaction within the community of scientists to be indispensable in constituting scientific objectivity. The social interaction should, inter alia, assure the publicity of research and the possibility of cultivating critical points of view. When these conditions of critical social interaction are lacking, objectivity is threatened, something which is the case in the current commercialization of the research process in science, according to Jukola.

Jukola points at the impact of commercialization and the lack of appropriate socialepistemic interaction - thus undermining epistemic trustworthiness and scientific objectivity - at different stages of the research process, i.e. when choosing the research approach, when choosing the study design, and, when disseminating results and data.

First, as concerns the research approach, some fields lack epistemic diversity, i.e., a plurality of well-developed alternative research approaches. Jukola refers here to research in psychiatry, where the pharmaceutical industry mainly supports research approaches focusing on the biological factors and cures involving drugs to be patented rather than, for instance, behavioral therapies or diets. As a consequence, alternative research approaches receive less funding and this undermines the possibilities of critical social interaction among competing research approaches in order to examine each other's background assumptions, etc. (A critique well in line with Jan De Vos' contribution.) 
Second, methods chosen when designing a study or medical trial should be up for scrutiny. Analysis has shown that medical trials funded by the industry more often show positive results for tested products than studies funded by other sources do. A social back-up system, the critical social-epistemic interaction, is required to make sure that methodological choices are not made in an unsound way favoring some particular outcome or making wanted results more likely, according to Jukola.

Third, attention should be paid to publication bias, i.e., positive findings being more likely to be published than negative or inconclusive ones. Is it due to the lack of space in journals? Or are companies reluctant to publish results that might undermine their products? Violating the principle of publicity might have serious consequences. The published research results will give a flawed, incomplete picture of the product studies (also affecting meta-analyses) and the community of researchers will be unable to evaluate the soundness of results.

Indeed, the social view on objectivity articulates the importance of critical social-epistemic interactions that disclose biases and mistakes, and, avoid the pernicious tendencies of commercialized science sketched above.

Just like Lacey, Jukola points at how the growing commercialization of science not only threatens its epistemic trustworthiness, but might also have a negative impact on society and on our democratic values. Both emphasize the importance of cultivating a plurality of research approaches and methodologies, that are sufficiently well-developed to criticize and interact seriously with one another. How this social-epistemic interaction exactly has to play out remains a topic to be further explored; what can we learn from democratic theory (as explored by King et al.), what are the implications for the responsibility of scientists themselves (as discussed by Lacey), how do we have to adjust our own views of science (e.g., scientific objectivity constituted in a social way rather than by the individual scientist, as advocated by Jukola)?

\section{Connecting Both Disciplines}

As said, one of the things we hope to achieve with this volume is a rapprochement between social epistemology and the philosophy of the humanities. In this respect, it is striking that the papers on dissensus and consensus with a background in social epistemology use a rather restricted number of classical case studies such as climate science, creationism and the influence of the pharmaceutical industry on medical science. We suggest that they can expand and enrich their repertoire of case studies by looking at some less classical, but nevertheless very important cases in the humanities. The best example is probably Peter Stearns' essay on World History. His story of the fortune of World History as an academic subdiscipline and a part of the history curriculum makes it clear that history is intimately connected to politics and society, and that a change in the latter will almost always result in a change in the former. For example, the emphasis on 'Western Civilization' as a historical theme originated in the first half of the twentieth century, as a result of the Western identity crisis during and after the two World Wars, and as a form of legitimation of the United States as a centuries-old civilization. In the course of the twentieth century, World History followed the course of politics, generally appearing together with progressive and multiculturalist governments, and disappearing again when conservatives come to power. In the United States, world history hesitantly became a part of higher education curricula when students became more ethnically diverse and could no longer identify with the perspective of Western Civilization. Conservatives, however, used the very same argument in exactly the opposite way: if ethnic minorities failed to identify with Western history, they should get not less, but more education in Western civilization, 
so that they eventually accept the dominant values of the nation. This does not only happen in the United States, but also in, for example the Netherlands and Australia, where history is expected to breed good, decent and nationalist citizens. To a somewhat lesser extent, this is also true for the European Union, which consistently promotes the idea of 'Europe' as a quasi-civilization, rooted in a common history of EU member states.

The history of world history, admirably described by Stearns, is absolutely loaded with the messy forms of dissent King, Morgan-Olsen and Wong describe: politicians use history as a way to profile themselves: proponents of world history are often represented as naive multi-culturalists, while proponents of Western Civilization are being called imperialists and nationalists. Dissent about teaching and researching history often, if not always, hides some other, more fundamental dissent about how a society should be organized, and how it should deal with differing values and conflicting identities.

Nevertheless, one should not be led to believe that this entails that science is a mere passive follower of social developments. As Markus Seidel argues, the connection between science and society also means that science is or should be able to change society for the better. Seidel investigates this theme in a historical way, by going back to the thought of Otto Neurath and Karl Mannheim. Neurath believed that scientists should uncompromisingly strive towards a more rational society. Mannheim, on the other hand, believed that science should take up a more distanced role, and identify implicit presuppositions. Jan De Vos offers us an example, by identifying the implicit presuppositions of neuro-education. De Vos shows, among others, how the popular and the academic discourses on all things neuro- are more closely connected than is often thought. Both the neurosciences themselves and the popular discourse on neurosciences and the DSM betray the desire to change the modern subject. By indentifying what is left implicit in this process, we can be able to control it somewhat, and emancipate ourselves from the perceived burden of badly understood science. In this sense, De Vos' paper corresponds to Mannheim's view on the influence of science on society, and offers an answer to Seidel's concern that modern social epistemology runs the danger of leaving the urge to change society itself behind.

\section{Social Epistemology and Potatoes}

Finally, we could not possibly write an introductory paper to a volume about the connection between science and society without mentioning the societal context of this volume itself. The idea for this volume was born in the aftermath of the 'potato'-controversy in Flanders in 2012 and 2013. Briefly put, what happened was the following: In 2011, the Flemish Institute for Biotechnology, a world- leading research centre at Ghent University connected to BASF and Bayer Crop Science, staged an open field trial of a new type of genetically modified potato in the Flemish city of Wetteren. This prompted a reaction from farmers and anti-GMO activists, who held a manifestation at the site of the GMO potatoes in May 2011. During the event, some protesters tried to enter the test field, and eventually managed to pull out some potatoes before they were stopped by the police. In the aftermath of the event, the activists' spokesperson, who was a postdoctoral researcher at the University of Leuven, was fired almost immediately by the university. The motivation for her forced resignation was particularly interesting: the university management implicitly used the idea of "crimes against science": they deemed it unethical for a researcher of their institution to be associated with people who dared to intervene in the free course of science. The events in Wetteren and the resignation of the activists' spokesperson prompted an extensive media debate. Although the large majority of politicians and a number of academics agreed with the Leuven University 
management, many academics, among others two of the authors of this article, protested: wasn't it hypocritical to condemn an academic for intervening in the free course of science, when all she did was make exactly the same point: that GMO research had become too dependent of multinationals to be legitimately called free and independent research?

This is one of the points both Lacey and Jukola warn us for in their papers: the biotechnology sector is very much intertwined with the industry, and hence will be subject to the commercial logic of the private market. Hence, if there is no democratic institution that can counterbalance these interests (such as in the case of the GMO potatoes), GMO research will automatically generate a positive bias towards research that has the potential to generate high profits, and a negative one with respect to potential risks or negative results.

One of the arguments that was often heard in favour of the GMO potatoes was that laboratory and secluded fields test had proven that they were more resistant to pesticides than regular potatoes. Hence, so the proponents say, GMO potatoes would, in theory, lead to a less pesticide-intensive agriculture. However, in his contribution to this volume, Hugh Lacey discusses this very theme when treating the example of transgenic seeds and plants research. He convincingly argues that the legitimacy of using transgenics-now and in the future-does not only depend on the demonstrated efficacy of them, but also on the (agroecological, organic, biodynamic, indigenous, etc.) alternatives and risks of the respective approaches (in the context in which they are employed). If the commercialization of science leads to a research agenda that merely sponsors the research with which quick economic gain can be made, strengthening the current 'mainstream' approach developing transgeneics, then the future might not see any well-developed alternatives, nor the possibility of a critical interaction among a plurality of well-developed research approaches.

The potato-debates are also another example of the messy forms of social disagreement described by King et al. Some GMO-proponents tried to frame the discussion as a form of worldview agonism between science and progress on the one hand, and nature and neoluddism on the other. Most activists, however, firmly insisted that this was not the case, and that the debate was actually a debate about the intellectual freedom of the university, and of the effect of global multinational capitalism on our daily lives.

Many GMO-proponents also argued that the activists had no reason to resort to violent action, since they were free to express their views during their manifestations and, from time to time, on the opinion pages of serials and newspapers. The activists, on the other hand, stated that the alleged pluralism on freedom of speech was irrelevant, since their opinions and arguments were tolerated, but were not taken into account when it came to policy matters. Permission for publically funded GMO research and open field trials does run through a democratic process, but is controlled through a rather in-crowd commission appointed by the government. Again in terms of King, Morgan-Olsen and Wong: there was definitely pluralism and toleration, but no uptake. Hence, it is clear that the activists' statements about a lack of democratic debate about GMO's was justified, not in terms of toleration, but in terms of uptake. $^{3}$

If the potato-debates have showed us one thing, it might be this: there is a dire need of scholars who are able to think and write about the relation between science and society in an informed and nuanced way. In the course of the potato-debate it became clear that many scientists, academics and policy makers seemed to deny the idea of a connection between science and society. Many scientists argued that all they did was research, and that they were not to be held responsible in any way for the implementation of their research in the real

3 This does not imply that the authors intend to justify the use of force in dealing with contrary views, as was done by some of the protesters in terms of tampering with the crops and trespassing private property. 
world. The same goes for the majority of policy makers, who regarded the university as just another way of investing in technology and specialized industry, and did not bother about the long-term and global effects and risks.

The most important thing we try to achieve with this volume is to counterbalance these outdated ideas. Science is only one node in a network of social institutions, we believe it is vital for the future of science in an ever more complex and globalizing world to understand its role, and to take responsibility for it. We hope that this volume can be a contribution to this aim.

\section{References}

Anderson, B. (1991). Imagined communities: Reflections on the origin and spread of nationalism. London: Verso.

Beatty, J., \& Moore, A. (2010). Should we aim for consensus? Episteme, 7(3), 198-214.

Berger, S., \& Lorenz, C. (Eds.). (2008). The contested nation. New York: Palgrave Macmillan.

Cassirer, E. (1977). Philosophy of symbolic forms (Vol. 3). New Haven: Yale University Press.

Cassirer, E. (2003). Substance and function and Einstein's theory of relativity. Mineola: Dover Publications.

Dilthey, W. (2002). The formation of the historical world in the human sciences. Princeton: Princeton University Press.

Ehrecht, W. (1979). Soviet historians and the study of Russian imperialism. Bohlau: Cologne.

Goldman, A. (2014). Social Epistemology, The Stanford Encyclopedia of Philosophy (summer 2010 edition), Edward N. Zalta (Ed.) http://plato.stanford.edu/entries/epistemology-social/ (accessed 07/04/2014).

Husserl, E. (1970). The crisis of European sciences and transcendental phenomenology: An introduction to phenomenological philosophy. Evanston: Northwestern University Press.

Iggers, G. (1983). The German conception of history: The national tradition of historical thought from herder to the present. Hanover: Wesleyan University Press.

Jackman, S., \& Paul, M. S. (2006). The limits of deliberative discussion: A model of everyday political arguments. Journal of Politics, 68(2), 272-283.

Kitcher, P. (2001). Science, truth and democracy. Oxford: Oxford University Press.

Knowlton, J., \& Cates, T. ( Tra). (1993). Forever in the shadow of Hitler: the dispute about the Germans' understanding of history. New Jersey: Humanityies Press.

Kosolosky, L., \& Van Bouwel, J. (2014). Explicating ways of consensus-making in science and society: distinguishing the academic, the interface and the meta-consensus. In C. Martini \& M. Boumans (Eds.), Experts and consensus in social science, ethical economy (Vol. 50). doi:10.1007/978-3-319-08551-7_4.

Linenthal, E., \& Engelhardt, T. (1996). History wars. New York, Holt Paperbacks: The Enola Gay and Other Battles for the American Past.

Macintyre, S., \& Clark, A. (2003). The history wars. Carlton: Melbourne University Publishing.

Mill, J. S. (1859/1991). On liberty. In On liberty and other essays. Oxford: Oxford University Press.

Mutz, D. C. (2006). Hearing the other side: Deliberative versus participatory democracy. Cambridge: Cambridge University Press.

Reisch, G. A. (2005). How the cold war transformed philosopy of science: To the icy slopes of logic. Cambridge: Cambridge University Press.

Rickert, H. (1986). The limits of concept formation in natural science, a logical introduction to the historical sciences. Cambridge: Cambridge University Press.

Schmitt, F. F. (1987). Special issue: Social epistemology. Synthese, 73(1), 1-204.

Shera, J. (1970). Sociological foundations of librarianship. New York: Asia Publishing House.

Solomon, M. (2006). Groupthink versus the wisdom of crowds: The social epistemology of deliberation and dissent. The Southern Journal of Philosophy, 44, 28-42.

Solomon, M. (2007). The social epistemology of NIH consensus conferences. In H. Kincaid \& J. McKitrick (Eds.), Establishing medical reality: Essays in the metaphysics and epistemology of biomedical science. Berlin: Springer.

Sunstein, C. R. (2007). Republic.com 2.0. Princeton: Princeton University Press.

Tucker, A. (2003). The epistemic significance of consensus. Inquiry, 46(4), 21-501.

Van Bouwel, J. (2009). The problem with(out) consensus: The scientific consensus, deliberative democracy, and agonistic pluralism. In J. Van Bouwel (Ed.), The social sciences and democracy (pp. 121-142). London: Palgrave MacMillan. 
Weber, M. (2011a). The meaning of "Ethical Neutrality" in Sociology and Economics". In M. Weber (Ed.) The methodology of the social sciences (pp. 1-48). New Brunswick: Transaction Publishers (referred to us 2011a).

Weber, M. (2011b). Objectivity in social science and social policy. In Weber, M. (Ed.) The methodology of the social sciences (pp. 49-112). New Brunswick: Transaction Publishers. (referred to as 2011b).

Anton Froeyman is a postdoctoral researcher at Ghent University (Belgium) who is interested in every kind of theoretical reflection on history. His research focuses on the ethics of history and historical experience. As such, he also interested in phenomenology and continental ethics, particularly in the philosophy of Emmanuel Levinas. Anton also published on matters of causation in analytical metaphysics. His research results have been published in journals such as History and Theory, Historical Methods, Philosophia, Rethinking History and Tijdschrift voor Filosofie.

Laszlo Kosolosky is a Phd researcher at Ghent University (Belgium), who is currently completing his dissertation entitled 'Optimizing social epistemic decision making processes: dealing with peer review and consensus making in scientific practice'. He has done research on social epistemological topics such as peer review, consensus formation, dissent, trust, epistemic integrity, values in science, pursuit-worthiness, discovery, creativity, and expertise. He published his work in journals such as Theoria, Tijdschrift voor Filosofie, Logique \& Analyse, Journal for General Philosophy of Science, Topoi, Accountability in Research, Philosophica, Ethiek en Maatschappij and Science and Engineering Ethics.

Jeroen Van Bouwel is a postdoctoral researcher at Ghent University (Belgium). His research deals with topics in philosophy of the social sciences, social epistemology and general philosophy of science, especially the conundrum of scientific pluralism. His articles have appeared in journals such as Economics and Philosophy, Philosophy of the Social Sciences, Perspectives on Science, History and Theory the Journal for the Theory of Social Behaviour. He is the editor of The Social Sciences and Democracy (Palgrave 2009) and author of Scientific Explanation (Springer 2013, co-authored with Erik Weber and Leen De Vreese). 